\title{
Preparation, Surface active properties, and Anticorrosion Application of some novel surfactants based on cottonseed oil and diethanolamine on carbon steel in $\mathrm{CO}_{2}$ environments
}

I. T. Ismayilov ${ }^{a}$, , V. M. Abbasov ${ }^{a}$, E. N. Efremenko ${ }^{b}$, L. I. Aliyeva ${ }^{a}$, S. A. Mamedxanova ${ }^{a}$, Hany M. Abd El-Lateef ${ }^{a} c^{*}$

${ }^{a}$ Mamedaliev Institute of Petrochemical Processes, National Academy of Sciences of Azerbaijan, AZ1025 Baku, Azerbaijan

${ }^{\mathrm{b}}$ Faculty of Chemistry, Lomonosov Moscow State University, 119991, GSP-1, 1-3 Leninskiye Gory, Moscow, Russia

${ }^{c}$ Chemistry Department, Faculty of Science, Sohag University, 82524 Sohag, Egypt

E-mail address: Hany_shubra@yahoo.co.uk

\section{ABSTRACT}

Novel surfactants were synthesized based on cottonseed oil and diethanolamine and the structures of these compounds were confirmed by FTIR spectroscopy. The surface and thermodynamic properties of these compounds have been investigated. The corrosion behavior of the synthesized surfactant corrosion inhibitors was evaluated by using potentiodynamic (Tafel) polarization curves, linear polarization resistance corrosion rate techniques. The experimental results showed that these inhibitors revealed a very good corrosion inhibition even at low concentrations. The protection efficiency increased with increasing inhibitor concentration, getting maximum values ranged between 87.37 and $97.91 \%$ at $100 \mathrm{ppm}$ after 20 hour of exposure. The adsorption process was found to obey the Langmuir adsorption isotherm.

\section{Indexing terms/Keywords}

Corrosion inhibitor; Carbon steel; Surfactants; Potentiodynamic polarization; Surface tension; Critical micelle concentration

\section{Academic Discipline And Sub-Disciplines}

Corrosion protection

\section{SUBJECT CLASSIFICATION}

Chemistry Subject Classification

TYPE (METHOD/APPROACH)

Experimental study

\section{Council for Innovative Research}

Peer Review Research Publishing System

\section{Journal: Journal of Advances in Chemistry}

\author{
Vol 1, No 1 \\ editor@cirworld.com \\ www.cirworld.com, member.cirworld.com
}




\section{INTRODUCTION}

Carbonic-acid corrosion ( $\mathrm{CO}_{2}$-corrosion) is one the most studied form of corrosion in oil and gas industry. Carbon Dioxide gas $\left(\mathrm{CO}_{2}\right)$ in oil/gas stream forms carbonic acid $\left(\mathrm{H}_{2} \mathrm{CO}_{3}\right)$ when dissolved in water (which is also contain in gas/crude oil reservoir/well) forms Carbonic acid $\left(\mathrm{H}_{2} \mathrm{CO}_{3}\right)$ with the characteristic that is more aggressive than hydrochloric acid at the same $\mathrm{pH}[1]$.

Mild steel is widely applied as the constructional material in many industries due to its excellent mechanical properties and low cost. As some of the important fields of application are acid pickling, industrial cleaning, acid descaling, oil-well acidizing and petrochemical processes, the main problem of applying mild steel is its dissolution in chloride solutions. Chloride is well known to play a crucial role in steel corrosion, but its effect depends on whether the aqueous system is deaerated (oxygen-free), oxygen-aerated, or deaerated but CO2-bearing. In deaerated acidic solutions, chloride accelerates the anodic kinetics of iron dissolution via a catalytic mechanism [2-5]. In deaerated neutral and alkaline solutions, a corrosion scale is usually formed.

Several methods are present for corrosion prevention. One of such methods is the use of the organic inhibitors [6-11]. The use of inhibitors is the most economical and practical method in reducing corrosive attack on metals [12, 13]. Surfactants corrosion inhibitors are the most effective means of protection to sever corrosion of carbon steel constructions in petroleum industry. The adsorption of a surfactant on a metal surface can markedly change the corrosion-resistance properties of the metal $[14,15]$. Therefore, the study of relation between the adsorption and corrosion inhibition is of great importance. Recently, many surfactants have been widely used as corrosion inhibitors for mild steel alloys in $\mathrm{CO}_{2}$ environments $[16,17]$. The compounds act through a process of surface adsorption. The efficiency of inhibitors depends on the nature of the metal surface and electrochemical potential at the interface. The structure of the inhibitor itself, which includes the number of adsorption active centers in the molecule, their charge density, the molecule size, the mode of adsorption, the formation of metallic complexes and the projected area of the inhibitor on the metallic surface also has effect on the efficiency of inhibitors [18-20].

The purpose of this paper is to evaluate the behavior of novel surfactants synthesized based on cottonseed oil and diethanolamine as corrosion inhibitors in the $\mathrm{CO}_{2}$ corrosion of 1018 carbon steel using potentiodynamic (Tafel) polarization curves, linear polarization resistance corrosion rate techniques in an environment containing $1 \% \mathrm{NaCl}$ solution and $\mathrm{CO} 2$. It was also the purpose of the present work to test the experimental data obtained from LPR corrosion rate measurements with several adsorption isotherms at the investigated temperature, in order to gain more information on the mode of adsorption.

\section{EXPERIMENTAL PROCEDURE}

\section{Chemical composition of carbon steel alloy}

Electrodes are made of carbon steel grade $080 \mathrm{~A} 15$ and have an area of $4.55 \mathrm{~cm} 2$. The mechanical properties of the carbon steel measured at room temperature were provided by supplier shown as follows: tensile strength equal to 490 $\mathrm{MPa}$ and elongation to failure equal to $16 \%$. The Chemical composition of low carbon steel used in this study was given in Table 1. The data was provided by European Corrosion Supplies Ltd.

Table 1: Chemical composition of low carbon steel alloy.

\begin{tabular}{ccccccccc}
\hline Element & Si & Ni & $\mathbf{C r}$ & $\mathbf{C}$ & $\mathbf{S}$ & $\mathbf{P}$ & Mn & Fe \\
\hline Content, (wt. \%) & 0.24 & 0.01 & 0.10 & 0.18 & 0.05 & 0.05 & 0.50 & Balance \\
\hline
\end{tabular}

\section{Synthesis of Surfactants}

Cottonseed oil was reacted with diethanolamine for 7 hours at $150-160{ }^{\circ} \mathrm{C}$. These processes produce fatty acid diethanolamine amide. Based on the last prepared compound sulfating syntheses were performed. The product is sulfated fatty acid diethanolamine amide. Six types from surfactants were synthesized in high purity by the following compositions: [R-CH- $\left(\mathrm{OSO}_{3} \mathrm{M}\right)-\mathrm{CON}-\left(\mathrm{CH}_{2}-\mathrm{CH}_{2}-\mathrm{OH}\right)_{2}$ ] (where $\mathrm{M}=\mathrm{Na}, \mathrm{K}, \mathrm{NH}_{4},-\mathrm{NH}-\mathrm{CH}_{2}-\mathrm{CH}_{2}-\mathrm{OH},-\mathrm{N}-\left(\mathrm{CH}_{2}-\mathrm{CH}_{2}-\mathrm{OH}\right)_{2}$ and $\left.-\mathrm{N}\left(\mathrm{CH}_{3}\right)_{2}\right)$. The chemical structure of the synthesized surfactants was characterized by using FT-IR, Spectrum BX spectrometer using KBr disks. List of the synthesized surfactants are shown in Table 2.

\section{Preparation of solutions}

The aggressive solution, $1 \% \mathrm{NaCl}$, was prepared by dissolving of analytical grade $\mathrm{NaCl}$ in distilled water. The concentration range of the prepared surfactants was from 25 to $100 \mathrm{ppm}$ used for corrosion measurements. All inhibitors solutions were prepared using a mixture from distilled water and alcohol in a different ratio.

\section{Corrosion measurements}

The measurements were performed on the rotating cylinder electrode. This electrode was used for one time. The reference electrode was $\mathrm{Ag} / \mathrm{AgCl}$ Electrode to which all potentials are referred. 
Before beginning the experiment, the prepared $1 \%$ - of sodium chloride solution was stirred by a magnetic stirrer for $60 \mathrm{~min}$ in $1000 \mathrm{ml}$ cell. Then this cell was thermostated at a temperature $50 \circ \mathrm{C}$ for 1 hour under a pressure of 0.9 bars. The solution was saturated with carbon dioxide. To remove any surface contamination and air formed oxide, the working electrode was kept at $-1500 \mathrm{mV}(\mathrm{Ag} / \mathrm{AgCl})$ for $5 \mathrm{~min}$ in the tested solution, disconnected shaken free of adsorbed hydrogen bubbles and then cathodic and anodic polarization was recorded. ACM Gill AC instrument connected with a personal computer was used for the measurements.

\section{The extrapolation of cathodic and anodic Tafel lines}

The extrapolation of cathodic and anodic Tafel lines was carried out in a potential range $\pm 100 \mathrm{mV}$ with respect to corrosion potential ( $\left.E_{\text {corr }}\right)$ at scan rate of $1 \mathrm{mV} / \mathrm{s}$.

\section{Linear polarization resistance corrosion rate}

The LPR method is ideal for plant monitoring offering an almost instantaneous indication of corrosion rate, allowing for quick evaluation of remedial action and minimizing unscheduled downtime. The prepared $1 \%$ - of the solution sodium chloride was stirred by a magnetic stirrer for $60 \mathrm{~min}$ in $4000 \mathrm{ml}$. The prepared solution poured into the 4 glass beakers $(1000 \mathrm{ml}$ for each one). Then these beakers were placed on a heater at $50 \circ \mathrm{C}$ for 1 hour under a pressure of 0.9 bars. The solution was saturated with carbon dioxide. After that, the electrodes were placed in the medium and are connected through a potentiometer ACM GILL AC. The surface of working electrode is cleaned by acetone before using, these electrodes are using for one time. After 1 hour, except for 1 beaker, the remaining 3 is fed with the suitable amount of inhibitor and continued supply of $\mathrm{CO}_{2}$ under pressure of 0.9 bar until the end of the experiment.

The potential of the working electrode was varied by a CoreRunning programme (Version 5.1.3.) through an ACM instrument Gill AC. The CoreRunning programme converts a corrosion current in $\mathrm{mA} / \mathrm{cm}^{2}$ to a corrosion rate in $\mathrm{mm} / \mathrm{year}$. A cylindrical carbon steel rod of the composition 080A15 GRADE STEEL was used as a working electrode. Gill AC technology allows measure DC and AC signals using standard Sequencer software. A small sweep from typically $-10 \mathrm{mV}$ to $+10 \mathrm{mV}$ at $10 \mathrm{mV} / \mathrm{min}$ around the rest potential is performed. The test conditions are summarized in Table 3 .

\section{Surface tension measurements}

The surface tensions were determined by DuNouy Tensiometer, Kruss Type 8451 and the temperature was maintained precisely at $25{ }^{\circ} \mathrm{C}$. Critical micelle concentration (CMC) values of surfactants were determined, according to the break points in plots of the surface tension versus In molar concentration of investigated surfactants.

Table 2: List of the synthesized surfactants includes, code number, name and structure.

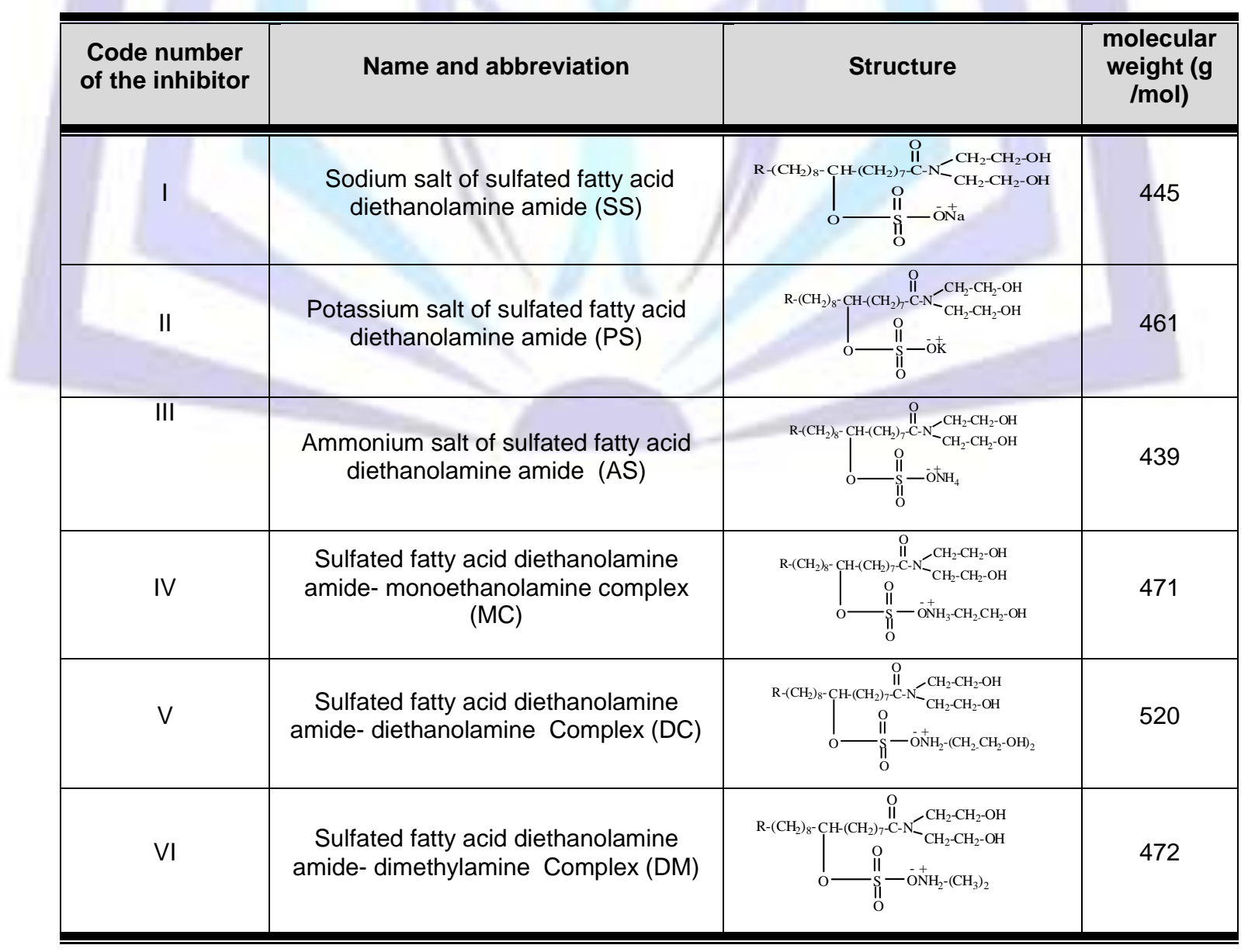


Table 3: Test parameters for corrosion experiments.

\begin{tabular}{|ll|}
\hline Material & C1018 carbon steel \\
\hline RCE outer surface area/cm2 & 4.55 \\
\hline Solution volume/L & 1.0 \\
\hline Temperature/ ${ }^{\circ} \mathrm{C}$ & 50 \\
\hline $\mathrm{pH}$ & $6.76 \rightarrow 5.68$ \\
\hline Inhibitor concentration, ppm & $25,50,75$ and 100 \\
\hline pCO2 /bar & 0.90 \\
\hline NaCl concentration/wt\% & 1.0 \\
\hline CO2 quality & $>99.7 \%$ \\
\hline Solution stirring & Stirred \\
\hline Corrosion measurements & $>\quad$ Linear Polarization Resistance corrosion rate \\
\hline
\end{tabular}

\section{RESULTS AND DISCUSSIONS \\ Chemical structure of the synthesized surfactants}

The structural characteristic of fatty acid diethanolamine amide before and after sulfating processes was confirmed by FT-IR spectroscopy in the range $4000-500 \mathrm{~cm}^{-1}$. The peak at about $1690 \mathrm{~cm}^{-1}$ is duo to the $-\mathrm{NH}-\mathrm{C}=\mathrm{O}$ carbonyl group, whereas the peak at $1450 \mathrm{~cm}^{-1}$ arises due to $\mathrm{C}=\mathrm{C}$ bond. This bond was broken after sulfating process. The peak at $1350 \mathrm{~cm}^{-1}$ is due to $\mathrm{S}-\mathrm{O}$ stretching absorption bands. FTIR spectrum showed that, the presence of OH group after sulfating process. It indicates the almost complete removal of $\mathrm{C}=\mathrm{C}$ bond by sulfating process and the process occur only on $\mathrm{C}=\mathrm{C}$.

The FT-IR for compound $\mathrm{V}$ showed an absorption band at the $2325 \mathrm{~cm}^{-1}$ region, indicating that formation ammonium ion $\left({ }^{+} \mathrm{NH}_{2}\right)$. In addition, there was a strong band at $890 \mathrm{~cm}^{-1}$, indicating the presence of multiple $\left(\mathrm{CH}_{2}\right) \mathrm{groups}$. The very strong band at the 2850 region was due mainly to the methyl asymmetric stretching vibration. The sharp band at $2925 \mathrm{~cm}^{-1}$ was observed for the investigated compounds due to the stretching vibration of the symmetric methylene group. The FT-IR absorption spectra confirmed that the disappearance of $-\mathrm{OH}$ band of $-\mathrm{SO}_{2}-\mathrm{OH}$ (broad band), this confirmed the transfer of proton of acid to nitrogen atom of amine to form ${ }^{+} \mathrm{NH}_{2}$ group. The results are generally in agreement with the expected correlations.

\section{Potentiodynamic (Tafel) polarization measurements}

Figure 1 represents the anodic and cathodic potentiodynamic polarization curves of mild steel alloy in $\mathrm{CO}_{2-}$ saturated $1 \% \mathrm{NaCl}$ solution in the absence and presence of different concentration of inhibitor I. The corrosion current density $\left(I_{c o r r}\right)$ and corrosion potential $\left(E_{c o r r}\right)$ were obtained by the extrapolating anodic and cathodic Tafel lines of polarization curves $[21,22]$. The results showed that a marked dependence of $I_{\text {corr }}$ of mild steel alloy on the surfactant concentrations. The surfactant inhibit both cathodic and anodic parts of the polarization curves, the shape of the curves are not modified on adding the plant extracts or by increasing the concentration, but the more pronounced behaviour that the curves produces a little shift on the anodic region and a greater shift on the cathodic region.

The adsorbed inhibitor blocks either the anodic or cathodic reaction or both. The effect of the inhibitor may be due to changes in the electric double layer, by reducing metal reactivity, or by the inhibitor participation in partial electrode reaction and by formation of a physical barrier. The adsorbed inhibitor may not cover the entire metal surface, but occupies sites which are electrochemically active and thereby reduces the extent of anodic or cathodic reaction or both. The corrosion rate will be decreased in proportion to the extent to which the electrochemically active sites are blocked by the adsorbed inhibitor.

Steady state of open circuit corrosion potential $\left(E_{\text {corr }}\right)$ for the investigated electrode in the absence and presence of the studied inhibitor was attained after 50-60 min from the moment of immersion. The inhibition efficiency expressed as percent inhibition $(\eta \%)$ is defined as [23]:

$$
\eta \%=\frac{I_{\text {uninh. }}-I_{\text {inh. }}}{I_{\text {uninh. }}} \times 100
$$


where $l_{\text {uninh. }}$ and $l_{\text {inh. }}$ are the uninhibited and inhibited corrosion currents. The inhibited corrosion currents are those determined in the presence of the studied surfactants used in this investigation. The uninhibited corrosion currents were determined in pure (inhibitor free) $\mathrm{CO}_{2}$-saturated $1 \% \mathrm{NaCl}$ solution at the same temperature. The electrochemical parameters $E_{\text {corr }}, I_{\text {corr }}$ inhibition efficiency $(\eta \%)$, anodic and cathodic Tafel slopes $\left(\beta_{\mathrm{a}}, \beta_{\mathrm{c}}\right)$ obtained from the polarization measurements were listed in Table 3. The data in exhibited that, the corrosion current density $\left(I_{\text {corr }}\right)$ decreases, and the inhibition efficiency $(n \%)$ increases as the concentration of inhibitor is increased. These results suggest that retardation of the electrodes processes occurs, at both cathodic and anodic sites, as a result of coverage of these sites by surfactant molecule. The increase of inhibitor efficiency with increasing the concentration can be interpreted on the basis the adsorption amount and the coverage of surfactant molecule, increases with increasing concentration [24]. The $E_{\text {corr }}$ of carbon steel shifted to the positive side by addition of surfactants I, II and III and the shift increased with increasing concentration of inhibitor, indicating that the inhibitor reduces the anodic reaction. It was explained that this shift in $E_{\text {corr }}$ is due to active sites blocking effect that occurs when an inhibitor is added [25]. In the presence of inhibitors $\mathbf{V I}, \mathbf{V}$ and $\mathbf{V I}$, $E_{\text {corr }}$ values were shifted slightly toward both cathodic and anodic directions and did not show any definite trend in $\mathrm{CO}_{2-}$ saturated brine. This may be considered due to the mixed-type behaviour of the studied surfactants. It can be observed, the shift in $E_{\text {corr }}$ that is characteristic of anodic and anodic/cathodic inhibitor [25].

The fact that the slopes of the cathodic $\left(\beta_{c}\right)$ and anodic $\left(\beta_{\mathrm{a}}\right)$ Tafel lines in Table 4 are approximately constant and independent of inhibitor concentration. These results indicate that this inhibitors act by simply blocking the available surface area. In other words, the inhibitor decreases the surface area for corrosion of the investigated metal, and only causes inactivation of a part of the surface with respect to corrosive medium [24]. On the other hand, the cathodic Tafel slopes $\left(\beta_{\mathrm{c}}\right)$ are also found to be greater than the respective anodic Tafel slopes $\left(\beta_{\mathrm{a}}\right)$. These observations are correlated with the fact that the anodic exchange-current density values are less than those of the cathodic counter parts. It can be concluded that the overall kinetics of corrosion of carbon steel alloy in $\mathrm{CO}_{2}$ saturated solution are under cathodic control.

Data in Table 4 shows that the inhibition efficiency increased with increasing the inhibitor concentrations. The inhibition efficiency of the investigated surfactants was increased in the following order: II $>$ I $>$ V $>$ IV $>$ III $>$ VI in the presence of $100 \mathrm{ppm}$ of investigated inhibitors. Conclusively, the surfactant inhibitor, having near unity $\theta$ (see Table 4), was considered as a good physical barrier shielding the corroding surface from corrosive medium and dumping the corrosion rate of carbon steel significantly.

Table 4: Corrosion parameters obtained from Tafel polarization for carbon steel in CO2-saturted $1 \% \mathrm{NaCl}$ solution in the absence and presence of different concentrations of the prepared surfactants at $50{ }^{\circ} \mathrm{C}$.

\begin{tabular}{|c|c|c|c|c|c|c|c|}
\hline $\begin{array}{c}\text { Inhibitors } \\
\text { Code }\end{array}$ & $\begin{array}{c}\text { Conc. of } \\
\text { inhibitor } \\
(\mathbf{p p m})\end{array}$ & $\begin{array}{c}-E_{\text {corr }}(\mathbf{m V} \\
(\mathbf{A g} / \mathbf{A g C l}))\end{array}$ & $\begin{array}{c}\boldsymbol{I}_{\text {corr }} \\
\left(\mathbf{m A c m}^{-2}\right)\end{array}$ & $\begin{array}{c}\boldsymbol{\beta}_{\mathrm{a}} \\
\left(\mathbf{m V d e c}^{-1}\right)\end{array}$ & $\begin{array}{c}-\boldsymbol{\beta}_{\mathbf{c}} \\
\left(\mathbf{m V d e c}^{-1}\right)\end{array}$ & $\boldsymbol{\theta}$ & $\eta \%$ \\
\hline Absence & 0.0 & 687 & 0.389 & 44 & 107 & --- & --- \\
\hline \multirow{3}{*}{ I } & 25 & 677 & 0.040 & 43 & 106 & 0.82 & 89.51 \\
& 50 & 675 & 0.033 & 34 & 108 & 0.86 & 91.27 \\
& 75 & 671 & 0.024 & 45 & 113 & 0.89 & 93.60 \\
& 100 & 664 & 0.012 & 46 & 111 & 0.97 & 96.84 \\
\hline \multirow{3}{*}{ II } & 25 & 679 & 0.039 & 44 & 110 & 0.84 & 89.88 \\
& 50 & 678 & 0.032 & 44 & 105 & 0.87 & 91.59 \\
& 75 & 675 & 0.024 & 47 & 109 & 0.91 & 93.81 \\
& 100 & 667 & 0.011 & 43 & 114 & 0.97 & 96.94 \\
\hline \multirow{3}{*}{ III } & 25 & 683 & 0.079 & 44 & 111 & 0.81 & 79.46 \\
& 50 & 681 & 0.069 & 49 & 109 & 0.85 & 82.17 \\
& 75 & 679 & 0.050 & 44 & 108 & 0.89 & 86.99 \\
& 100 & 677 & 0.044 & 42 & 105 & 0.97 & 88.66 \\
\hline \multirow{3}{*}{ IV } & 25 & 700 & 0.193 & 51 & 106 & 0.79 & 50.27 \\
& 50 & 693 & 0.125 & 47 & 113 & 0.84 & 67.77 \\
& 75 & 684 & 0.090 & 45 & 111 & 0.89 & 76.61 \\
& 100 & 687 & 0.032 & 42 & 110 & 0.95 & 91.73 \\
\hline
\end{tabular}




\begin{tabular}{|c|c|c|c|c|c|c|c|}
\hline & 25 & 691 & 0.146 & 40. & 106 & 0.67 & 62.38 \\
$\mathbf{V}$ & 50 & 683 & 0.095 & 43 & 103 & 0.74 & 75.53 \\
& 75 & 690 & 0.069 & 45 & 106 & 0.82 & 82.17 \\
& 100 & 685 & 0.025 & 47 & 104 & 0.91 & 93.54 \\
\hline \multirow{3}{*}{ VI } & 25 & 690 & 0.095 & 47 & 108 & 0.73 & 75.37 \\
& 50 & 680 & 0.083 & 46 & 105 & 0.78 & 78.66 \\
& 75 & 695 & 0.060 & 45 & 106 & 0.84 & 84.47 \\
& 100 & 683 & 0.052 & 46 & 113 & 0.92 & 86.50 \\
\hline
\end{tabular}

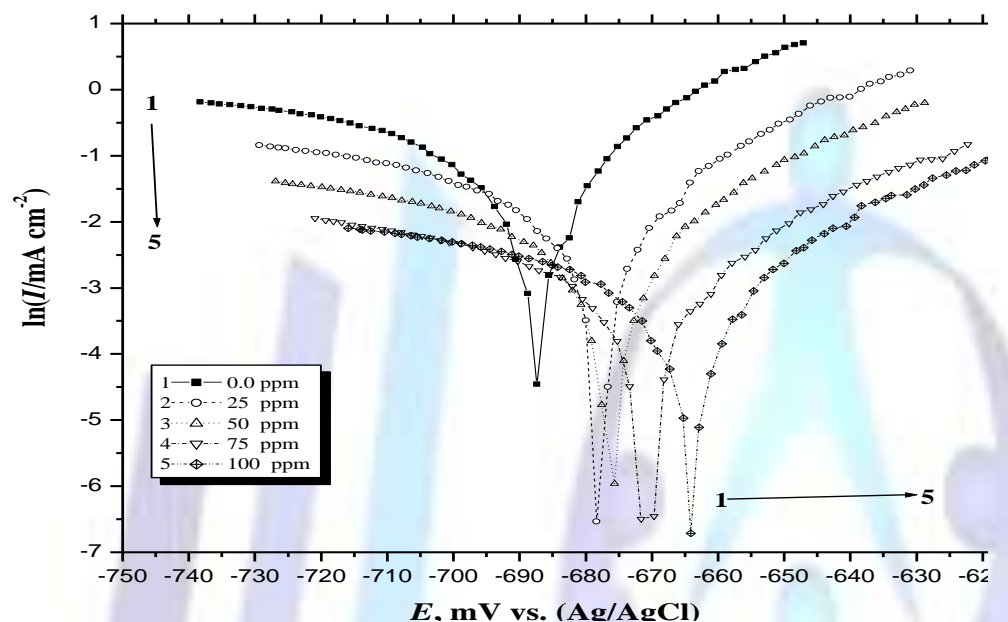

Fig. 1: Tafel polarization curves for carbon steel in CO2-saturated brine containina different concentration of inhibitor (I) at $50^{\circ} \mathrm{C}$.

\section{LPR Corrosion Rate}

LPR test has been performed in brine saturated with $\mathrm{CO}_{2}$ at $50{ }^{\circ} \mathrm{C}$, in turbulence fluid stream during 20 hours. Figures 2 and 3 show that, the change in corrosion rate (CR) with time for carbon steel in $\mathrm{CO}_{2}$-saturated $1 \% \mathrm{NaCl}$ solution containing different concentrations form inhibitors $\mathbf{I}$ and $\mathbf{V}$ at $50{ }^{\circ} \mathrm{C}$. The inhibitor was added after 1 hour of exposure because at this time the corrosion potential got stable, allowing the measurement of the CR prior the injection of the inhibitor. The initial corrosion rate, without inhibitor, was measured to be between 3.45 and $5.03 \mathrm{~mm}^{-1}$. It can be observed from Figure 1 that, the $\mathrm{CR}$, in the absence of inhibitor, tends to increase with time. The increase in CR has been attributed to the galvanic effect between the ferrite phase and cementite $\left(\mathrm{Fe}_{3} \mathrm{C}\right)$ which is a part of the original steel in the non-oxidized state and accumulates on the surface after the preferential dissolution of ferrite $(\alpha-\mathrm{Fe})$ into $\mathrm{Fe}^{2+}[26]$. $\mathrm{Fe}_{3} \mathrm{C}$ is known to be less active than the ferrite phase. Therefore, there is a preferential dissolution of ferrite over cementite, working the former as the anode and latter as the cathode, favoring the hydrogen evolved reaction (HER) during the corrosion process [27].

Variation of the corrosion rate for inhibitors $\mathbf{I}$ and $\mathbf{V}$ at different concentrations are presented in Figures 2 and $\mathbf{3}$. Corrosion parameters were calculated on the basis of LPR corrosion rate test. The inhibition efficiency ( $\eta$ \%) and surface coverage $(\theta)$ were calculated according to the following equations:

$$
\eta \%=\frac{C R_{0}-C R_{i}}{C R_{0}} \times 100
$$

$$
\text { Surface coverage }(\theta)=\theta=1-\frac{C R_{i}}{C R}
$$

where $C R_{0}$ is the corrosion rate without inhibitor and $C R_{i} C R^{R}$ the corrosion rate when inhibitor is present. It can be seen that the presence of inhibitors results a high decrease in the rate of corrosion. In the case of these inhibitors, the corrosion rate decreases as the inhibitor concentration increases, getting maximum inhibition efficiency ranged between 87.37 and $97.91 \%$ at 100 ppm after 20 hour of exposure (Table 5). This trend may results from the fact that adsorption and surface coverage increase with the increase in concentration; thus the surface is effectively separated from the medium. 
Table 5 shows the calculated values of corrosion rates, the inhibition efficiencies and the surface coverage in the absence and presence of different concentrations of different inhibitors at $50{ }^{\circ} \mathrm{C}$. The data exhibited that, the corrosion rates, the inhibition efficiencies and the surface coverage are found to depend on the concentrations of the inhibitors. The corrosion rate (CR) are decreased, and the inhibition efficiencies $(\eta \%)$ and the surface coverage $(\theta)$ are increased with the increase of the surfactant concentrations. This indicates that the inhibitory action of the inhibitors against carbon steel corrosion can be attributed to the adsorption of these molecules on the metal surface, limits the dissolution of carbon steel, and the adsorption amounts of surfactants on carbon steel increase with concentrations in the corrosive solutions. The maximum decrease in the corrosion rate was observed for inhibitor (II) and the inhibition efficiency of the investigated surfactants was increased in the following order: II $>$ I $>$ V $>$ IV $>$ III $>$ VI. There was an increase in the efficiency of corrosion inhibition with increasing concentration, Due to their containment of $\mathrm{C}=\mathrm{O}$, oxygen, nitrogen and sulfur groups these molecules contribute towards inhibition, and effectively protecting the surface. Adsorption of these surface active molecules forms thin inhibitor films on the metal surface which in order relatively isolate the metal surface from the corrosive environment causing much reduced corrosion rates. Inhibition efficiency of these films depends on various factors including but not limited to corrosivity of the environment, concentration of the active inhibitor molecules, any synergetic effects with other molecules present in the environment and/or flow/shear effects.

The high inhibition efficiency obtained in $\mathrm{CO}_{2}$ - saturated $1 \% \mathrm{NaCl}$ solution in the presence of studied complex surfactants can be attributed to the formation of a protective film of iron carbonate $\left(\mathrm{FeCO}_{3}\right)$ in the metal surface [14]. The properties of the formed layers and its effect on the corrosion rate are important factors to take into account when studying the corrosion of carbon steels in $\mathrm{CO}_{2}$-saturated solutions. Ogundele and White suggested that, iron carbonate, $\mathrm{FeCO}$, may be important in the formation of protective layers on steel surface [28]. The formation of iron carbonate can be explained by using the following Eq.[14].

$$
\mathrm{Fe}^{2+}+\mathrm{CO}_{3}^{2-} \rightarrow \mathrm{FeCO}_{3}
$$

By comparison between inhibition efficiency values $(n \%)$ which are calculated from both LPR corrosion rate and extrapolation of anodic and cathodic curves, we find that both have similar trend. In other words, the inhibition efficiency increases with increasing surfactant concentration, and the maximum inhibition efficiency values are obtained at $100 \mathrm{ppm}$ in the case of all investigated complexes. It is noteworthy that, the values of inhibition efficiency obtained by LPR corrosion rate results are greater (Table 5) than those obtained by cathodic and anodic extrapolation curves (Table 4). Such results can be attributed to the different interaction of surfactant molecule with the metal surface during cathodic and anodic polarization.

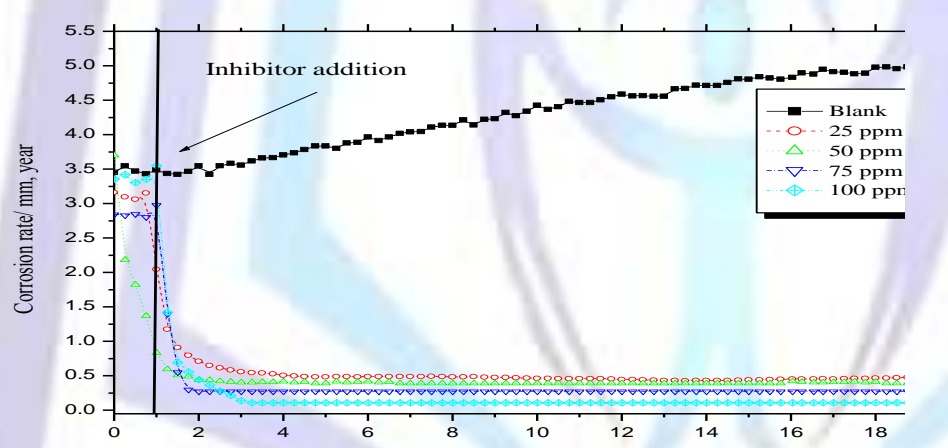

Figure 2: Variation of the Corrosion rate with time for carbon steel in $\mathrm{CO}_{2}$-saturated $1 \% \mathrm{NaCl}$ solution containing different concentrations of inhibitor I at $50^{\circ} \mathrm{C}$.

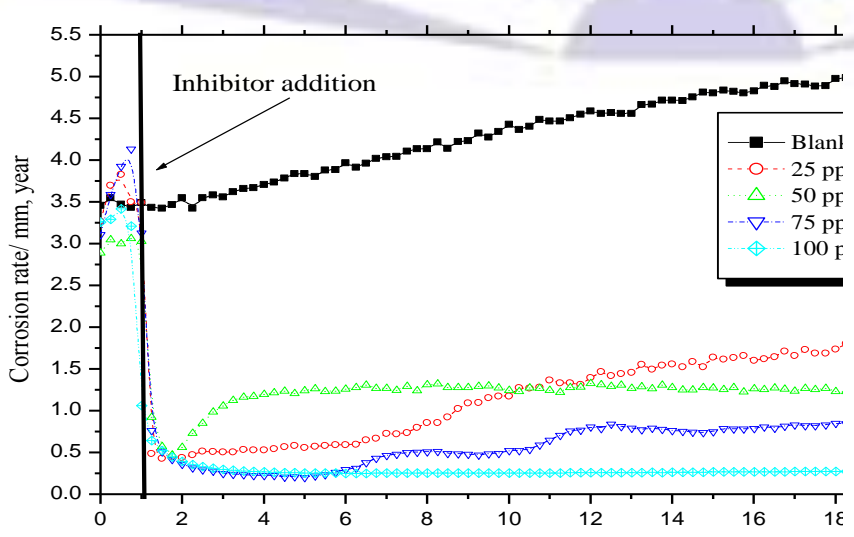

Figure 3: Variation of the Corrosion rate with time for carbon steel in $\mathrm{CO}_{2}$-saturated $1 \% \mathrm{NaCl}$ solution containing different concentrations of inhihitor $\mathrm{V}$ at $50{ }^{\circ} \mathrm{C}$. 
Table 5: The corrosion parameters obtained from LPR corrosion rate measurements for mild steel electrode in $\mathrm{CO}_{2}$-saturated brine in the absence and presence of various concentrations of investigated surfactants at $50{ }^{\circ} \mathrm{C}$.

\begin{tabular}{|c|c|c|c|c|}
\hline Inhibitors code & $\begin{array}{c}\text { Concentration, } \\
\text { ppm }\end{array}$ & $\begin{array}{c}\text { Corrosion rate } \\
\text { (mm/year) }\end{array}$ & $\begin{array}{c}\text { Surface } \\
\text { coverage } \\
\theta\end{array}$ & $\begin{array}{l}\text { The inhibition } \\
\text { efficiency, } \eta \%\end{array}$ \\
\hline Absence & 0.0 & 5.037 & ----- & ----- \\
\hline \multirow{4}{*}{ I } & 25 & 0.483 & 0.90 & 90.41 \\
\hline & 50 & 0.393 & 0.92 & 92.19 \\
\hline & 75 & 0.275 & 0.94 & 94.54 \\
\hline & 100 & 0.110 & 0.97 & 97.81 \\
\hline \multirow{4}{*}{ II } & 25 & 0.464 & 0.91 & 90.78 \\
\hline & 50 & 0.377 & 0.93 & 92.51 \\
\hline & 75 & 0.264 & 0.95 & 94.75 \\
\hline & 100 & 0.105 & 0.98 & 97.91 \\
\hline \multirow{4}{*}{ III } & 25 & 0.994 & 0.80 & 80.26 \\
\hline & 50 & 0.856 & 0.83 & 83.00 \\
\hline & 75 & 0.611 & 0.87 & 87.86 \\
\hline & 100 & 0.526 & 0.89 & 89.55 \\
\hline \multirow{4}{*}{ IV } & 25 & 2.479 & 0.50 & 50.78 \\
\hline & 50 & 1.589 & 0.68 & 68.45 \\
\hline & 75 & 1.139 & 0.77 & 77.38 \\
\hline & 100 & 0.370 & 0.92 & 92.65 \\
\hline \multirow{4}{*}{ V } & 25 & 1.863 & 0.63 & 63.01 \\
\hline & 50 & 1.194 & 0.76 & 76.29 \\
\hline & 75 & 0.856 & 0.83 & 83.00 \\
\hline & 100 & 0.278 & 0.94 & 94.48 \\
\hline \multirow{4}{*}{ VI } & 25 & 1.202 & 0.76 & 76.13 \\
\hline & 50 & 1.035 & 0.79 & 79.45 \\
\hline & 75 & 0.739 & 0.85 & 85.32 \\
\hline & 100 & 0.636 & 0.87 & 87.37 \\
\hline
\end{tabular}

\section{Surface tension and surface active properties}

The main importance of the critical micelle concentration (CMC) consists of the fact that at this concentration, most of the physical and chemical properties of the surfactant solutions present an abrupt variation. The values of surface tension $(\mathrm{g})$ were measured at $303 \mathrm{~K}$ for various concentrations of the mixed emulsifiers. The measured values of $(\mathrm{g})$ were plotted against In of the surfactant concentration, In C (Fig. 4). The intercept of the two straight lines designates the CMC, where saturation in the surface adsorbed layer takes place. The surface active properties of the surfactant, effectiveness $\left(\Pi_{\mathrm{cmc}}\right)$, maximum surface excess $\left(\Gamma_{\mathrm{max}}\right)$, and minimum area per molecule $\left(A_{\mathrm{min}}\right)$ were calculated using the following equations [29]

$$
\begin{aligned}
& \Pi_{\mathrm{cmc}}=\mathrm{Y}_{0}-\mathrm{\gamma}_{\mathrm{cmc}} \\
& \Gamma_{\max }=\frac{-1}{R T[\partial \gamma / \partial \ln C]_{T}}
\end{aligned}
$$




$$
\begin{gathered}
A_{\min }=\frac{1}{\Gamma_{\max } \times N_{A}} \\
\Delta G_{m i c}^{o}=R T \ln C M C \\
\Delta G_{a d s}^{o}=\Delta G_{m i c}^{o}-0.6023 \pi_{C M C} A_{\text {min }}
\end{gathered}
$$

Where $\partial y / \partial \mathrm{ln} C$ is maximum slope, $\gamma_{0}$ is the surface tension of pure water, $\gamma_{\mathrm{cmc}}$ the surface tension at critical micelle concentration, $N_{\mathrm{A}}$ is the Avogadro's number $\left(6.023 \times 10^{23}\right.$ molecules $\left./ \mathrm{mol}\right), R$ is the molar gas constant $(R=8.314$ $\mathrm{J} /(\mathrm{mol} \mathrm{K}))$ and $T$ is the absolute temperature $=\left(t^{\circ} \mathrm{C}+273\right), \Delta G_{m i c}^{o}$ is the Gibbs free energy of micellization, $\Delta G_{a d s}^{0}$ is the Gibbs free energy of adsorption [30].

The data presented in Table 6 show some of the surface active properties for the investigated surfactants. The results indicate that, the consequent increase in of $\Gamma_{\max }$ leads to crowding at the interface, which causes a decrease in $A_{\min }$ values. The values of effectiveness $\left(\Pi_{\mathrm{cmc}}\right)$ at $298 \mathrm{~K}$ indicate that the prepared compounds gives large reduction of surface tension at $\mathrm{CMC}$, so that, these compounds acts as effective corrosion inhibitors for carbon steel in $\mathrm{CO}_{2}$ - saturated $1 \% \mathrm{NaCl}$ solutions.

The free energy changes of micellization and adsorption showed negative sign showing the spontaneity of the two processes at $25^{\circ} \mathrm{C}$ (Table 6). Moreover, $\Delta G_{a d s}^{0}$ increase in negativity than $\Delta G_{\text {mic }}^{o}$. That showed the higher tendency of these surfactants towards adsorption rather than micellization. Then the adsorption will be accompanied with micellization at last. The tendency towards adsorption was referred to the interaction between the aqueous phases and the hydrophobic chains which pump the surfactant molecules to the interface [16].

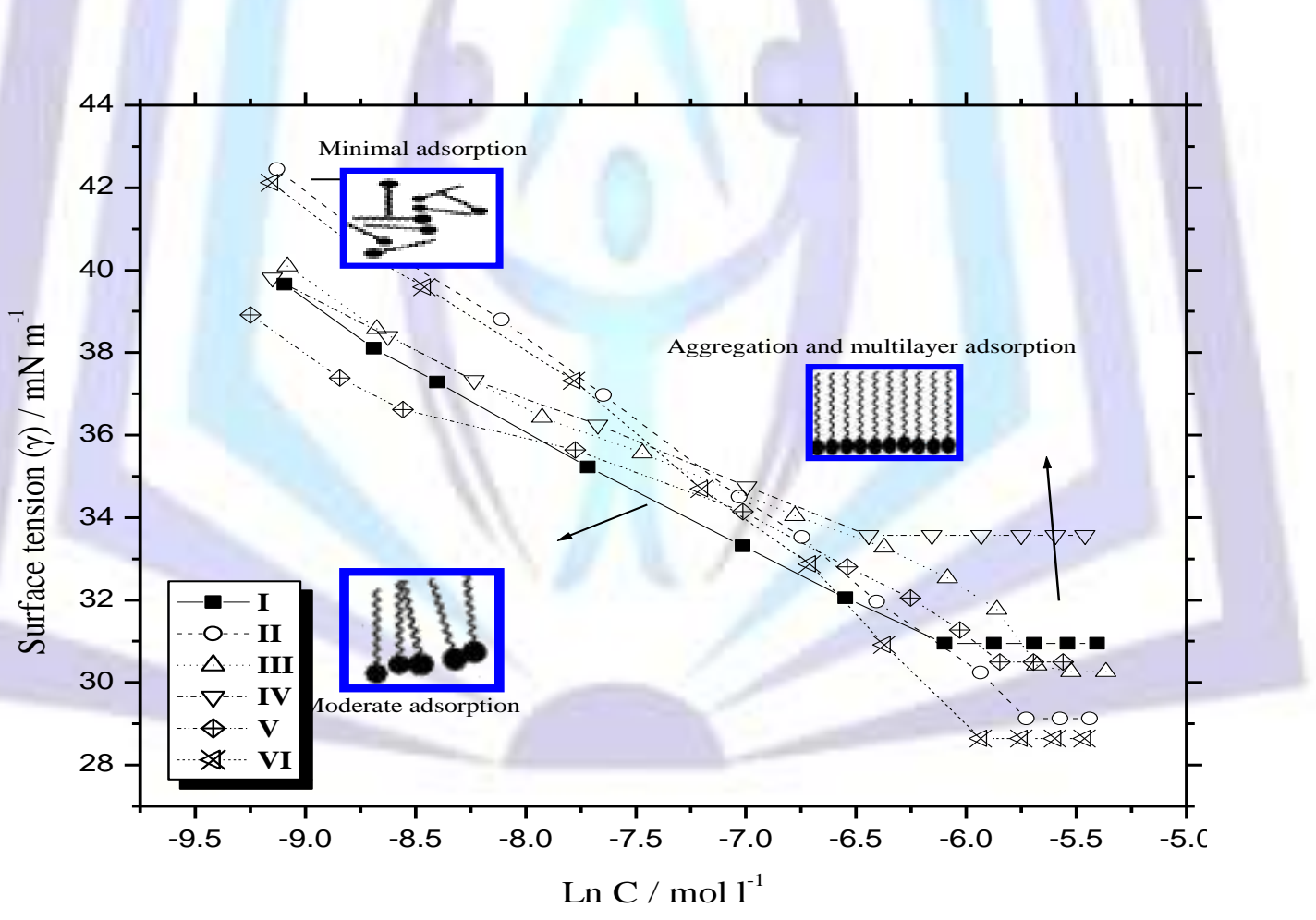

Fig. 4: Change of surface tension ( $\mathrm{y}$ ) with the concentration of the surfactants at 25

${ }^{\circ} \mathrm{C}$. 
$\underline{\text { Table } 6}$ The critical micelle concentration and surface parameters of the synthesized inhibitors.

\begin{tabular}{|c|c|c|c|c|c|c|c|}
\hline Inhibitor & $\begin{array}{c}\text { CMC } \\
\times 10^{-3} \\
(\mathrm{~mol} / \mathrm{l})\end{array}$ & $\begin{array}{c}Y \mathrm{cmc} \\
\left(\mathrm{mN} \mathrm{m}^{-1}\right)\end{array}$ & $\begin{array}{c}\Pi_{\mathrm{cmc}} \\
\left(\mathrm{mN} \mathrm{m}^{-1}\right)\end{array}$ & $\begin{array}{c}\Gamma_{\max } \\
\left.(\mathrm{mol} \mathrm{cm})^{-2}\right) \times 10^{-10}\end{array}$ & $\begin{array}{c}A_{\min } \\
\left(\mathrm{nm}^{2}\right)\end{array}$ & $\Delta G_{m i c}^{o}$ & $\Delta G_{a d s}^{0}$ \\
\hline $\bar{I}$ & 2.24 & 30.95 & 41.85 & 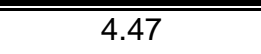 & 0.29 & -16.19 & $\overline{-31.9}$ \\
\hline II & 3.25 & 29.13 & 43.67 & 6.24 & 0.20 & -16.46 & -32.4 \\
\hline III & 3.41 & 30.42 & 42.38 & 6.81 & 0.29 & -14.80 & -29.2 \\
\hline IV & 3.18 & 33.57 & 39.23 & 4.81 & 0.17 & -15.80 & -31.1 \\
\hline $\mathbf{V}$ & 2.88 & 30.5 & 42.30 & 7.43 & 0.17 & -16.33 & -32.2 \\
\hline VI & 2.64 & 28.64 & 44.16 & 6.69 & 0.21 & -14.66 & -28.9 \\
\hline
\end{tabular}

\section{Adsorption isotherm}

The relation between $\mathrm{C} / \theta$ and $\mathrm{C}$ at $323 \mathrm{~K}$ was shown in Fig. 5 . A linear relation can be found between $\mathrm{C} / \theta$ and $\mathrm{C}$. The slope and the intercept were calculated. The slope was near unity. This behavior indicates that the adsorption of surfactants on carbon steel surface obeys Langmuir adsorption isotherm indicating that the inhibitor molecules were adsorbed on the metal surface and form a barrier, which isolated the metal surface from the electrolyte [31]. The slope of the isotherm deviates from unity as expected. This deviation may be explained on the basis of interaction between the adsorbed species on the metal surface by mutual repulsion or attraction [17].

The adsorption-desorption equilibrium constant $K_{\text {ads }}$ values could be calculated from the intercepts of the straight lines on the $\mathrm{C}_{\mathrm{inh}} / \theta$-axis, the $K_{\text {ads }}$ was related to the standard free energy of adsorption, $\Delta G_{a d s}^{o}$; with the following equation

$$
K_{a d s}=\frac{1}{55.5} \exp \left(-\frac{\Delta G_{a d s}^{o}}{R T}\right)
$$

The high value of the adsorption-desorption equilibrium constant as represented in Fig. 6, reflects the high adsorption ability of this inhibitor on the carbon steel surface [16].

In general, values of the free energy of adsorption $\Delta G_{a d s}^{o}$, up to $-20 \mathrm{~kJ} / \mathrm{mol}$ seem to suggest electrostatic interaction between the charged molecules and the charged metal (physical adsorption), while those more negative than $40 \mathrm{~kJ} / \mathrm{mol}$ involve charge sharing or transfer from the inhibitor molecules to the metal surface to form a coordinate type (chemisorption bonds) [14]. The decreasing value of $\Delta G_{a d s}^{o}$ reflects the increasing adsorption. The calculated values of $\Delta G_{a d s}^{o}$ for synthesized surfactants ranged between -25.91 and $-19.54 \mathrm{~kJ} / \mathrm{mol}$, indicating that the adsorption of the studied surfactants takes place through electrostatic interaction between the inhibitor molecule and the carbon steel surface so physicosorption was supposed. The negative values of $\Delta G_{a d s}^{o}$ indicate a spontaneous adsorption of the surfactants on the surface of investigated electrode [16]. The $\Delta G_{a d s}^{o}$ for inhibitor II (-25.91 kJ/mol) was less than other surfactants which indicate the stronger adsorption for inhibitor II more than other surfactants. 


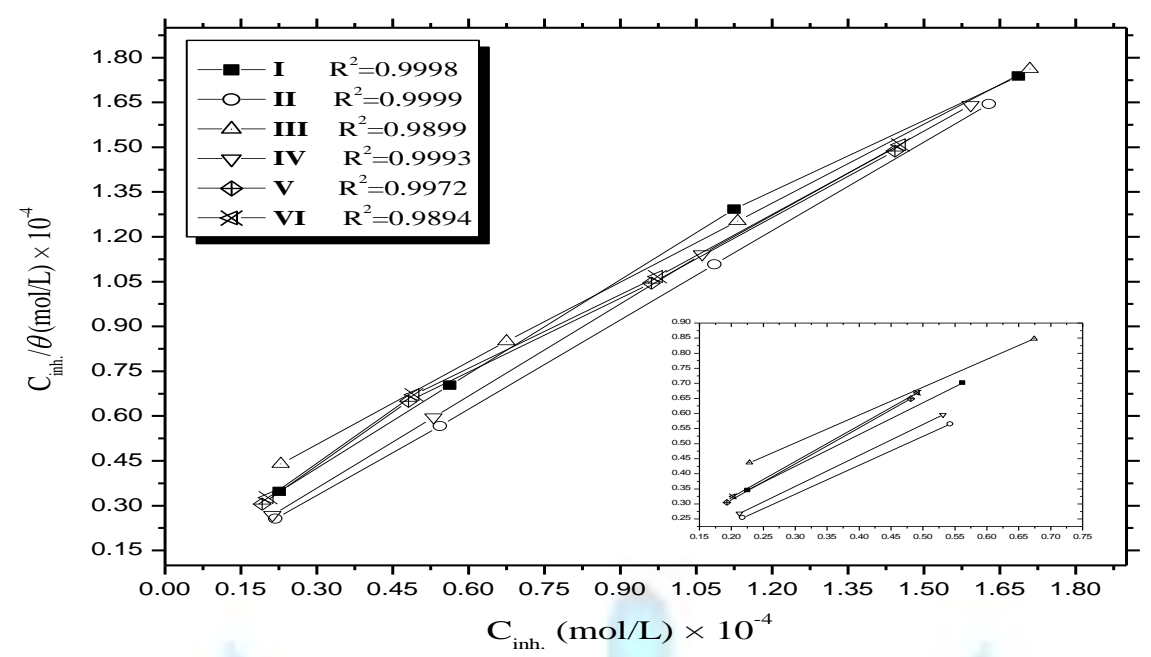

Figure 5: Curve fitting of the corrosion data obtained from LPR corrosion rate measurements for carbon steel in $\mathrm{CO}_{2}$ saturated brine containing various concentrations of inhibitors according to Langmuir adsorption isotherm

\section{CONCLUSIONS}

The conclusion could be drawn in the following points:

1. The inhibition properties of some new surfactants were tested by using LPR corrosion rate and potentiodynamic polarization measurements. According to the results, the prepared surfactants were good inhibitors for carbon steel in $\mathrm{CO}_{2}$-saturated $1.0 \% \mathrm{NaCl}$ solution.

2. The protection efficiency increased with increasing inhibitor concentration, getting maximum values ranged between 87.37 and $97.91 \%$ at 100 ppm after 20 hour of exposure.

3. The relative efficiencies of the three compounds studied in $1 \% \mathrm{NaCl}$ solution saturated with $\mathrm{CO}_{2}$ at $50{ }^{\circ} \mathrm{C}$ were found to be in the following order: II $>$ I $>$ V $>$ IV $>$ III $>$ VI.

4. Polarization curves showed that the inhibitors I, II and III and reduces the anodic reaction, but inhibitors $\mathbf{V I}, \mathbf{V}$ and $\mathbf{V I}$ was a mixed type.

5. The more negative values of free energies for adsorption ( $\Delta G_{a d s}^{0}$ ) than free energies for micellization ( $\Delta G_{\text {mic }}^{o}$ ) show that the investigated surfactants favor adsorption to micellization.

6. Adsorption of the inhibitor molecule onto carbon steel surface obeys Langmuir isotherm.

\section{REFERENCES}

[1] Zhang ,G., Chen, C., Lu, M., Chai, C., Wu Y., 2007. Mater. Chem. Phys.; 105, 331.

[2] Chin, R.J., Nobe, K., 1972. J Electrochem Soc, 119, 1457

[3] Darwish, N.A., Hilbert, F,, Lorenz, W.J, et al, 1973. Electrochim Acta, 18, 421

[4] Kuo, H.C., Nobe, K., 1978. J Electrochem Soc, 125, 853

[5] MacFarlane, D.R., Smedley, I.S., 1986. J Electrochem Soc, 133, 224.

[6] Hosseni, M., Mertens, S.F.L., Ghorbani, M., Arshadi, A.R., 2003. Asymmetrical Schiff bases as inhibitors of mild steel corrosion in sulphuric acid media, Mater. Chem. Phys.;78, 800-808

[7] Küstü, C., Emregül, C.K., Atakol, O., 2007. Schiff bases of increasing complexity as mild steel corrosion inhibitors in $2 \mathrm{M} \mathrm{HCl}$, Corros. Sci. 49, 2800- 2814.

[8] Quraishi, M.A., Ansari, F.A., Jamal, D., 2002. Thiourea derivatives as corrosion inhibitors for mild steel in formic acid, Mater. Chem. Phys.; 77, 687-690.

[9] Solmaz, R., Kardas, G., Yazici, B., Erbil, M., 2005. Inhibition effect of rhodanine for corrosion of mild steel in hydrochloric acid solution, Protec. Met. 41, 581-585 
[10] Bentiss, F., Lebrini, M., Vezin, H., Lagrenee, M., 2004. Experimental and theoretical study of 3-pyridyl-substituted 1,2,4-thiadiazole and 1,3,4-thiadiazole as corrosion inhibitors of mild steel in acidic media, Mater. Chem. Phys. 87, $18-23$.

[11] Shengtao Zhang, Zhihua Tao, Weihua Li, Baorong Hou, 2009. The effect of some triazole derivatives as inhibitors for the corrosion of mild steel in $1 \mathrm{M}$ hydrochloric acid, Appl. Surf. Sci. 255, 6757-6763

[12] Ali, S.A., Saeed, M.T., Rahman S.U., 2003. The isoxazolidines: a new class of corrosion inhibitors of mild steel in acidic medium, Corros. Sci.; 45, 253.

[13] Hosseini, S.M.A., Azimi, A., 2009. The inhibition of mild steel corrosion in acidic medium by 1-methyl-3-pyridin-2-ylthiourea, Corros. Sci. 51, 728-732.

[14] Abbasov, V. M., Abd El-Lateef, H.M., Aliyeva, L.I., Ismayilov, I.T., Qasimov, E. E., 2013. Efficient Complex Surfactants from the Type of Fatty Acids as Corrosion Inhibitors for Mild Steel C1018 in $\mathrm{CO}_{2}$-Environments, Journal of the Korean Chemical Society, 57(1), 25-34.

[15] Abbasov, V.M., Abd El-Lateef, H.M., Aliyeva, L.I., Ismayilov, I.T., 2013. Application of Some Surfactants Based On Corn Oil as Corrosion Inhibitors for Carbon Steel in $\mathrm{CO}_{2}$ Environments, NACE corrosion, Florida, USA, paper No. 2129.

[16] Abd El-Lateef, H.M., Abbasov, V.M., Aliyeva, L.I., Qasimov, E. E., Ismayilov I.T., 2012. LPR Corrosion Rate, Weight Loss Measurements and SEM Studies of the Effect of the Some Novel Surfactants as Corrosion Inhibitors for Carbon Steel in $\mathrm{CO}_{2}$-Saturated 1\% NaCl Solutions, Journal of Surfaces and Interfaces of Materials, 1, 1-11.

[17] Abd El-Lateef, H.M., Abbasov, V.M., Aliyeva, L.I., Ismayilov, T.I., Qasimov, E.E., Ahmadov, T .U., 2012. Novel anionic surfactants based on cottonseed oil and their corrosion inhibition efficiency for carbon steel in $\mathrm{CO}_{2}$ saturated solution, Global J. Phys. Chem., 3 14, 1-12.

[18] Soltani, N, Behpour, M, Ghoreishi, SM, Naeimi, H, 2010. Corros. Sci. $52,1351$.

[19] Obot, I.B., Obi-Egbedi, N.O., 2008. Surf. Rev. Lett. 15(6), 903.

[20] Obot, I.B., Obi-Egbedi, N.O., Umoren, S.A., Ebenso, E.E., 2010. Int. J. Electrochem. Sci. 5, 994.

[21] Tremont, R., De Jesus-Cardona, H., Garcia-Orozco J, Castro R.J., Cabrera C.R., 2000. J. Appl. Electrochem, 30, 737.

[22] Schultze, J.W., Wippermann, K., 1987. Electrochim. Acta, 32, 823.

[23] El-Sayed, A., Mohran, H.S., Abd El-Lateef, H,M., 2011. Inhibitive action of ferricyanide complex anion on both corrosion and passivation of zin c and zinc-nickel alloy in the alkaline solution, $\square$ Journal of Power Sources, 196, 6573-6582..

[24] Abdel Aal MS, Abdel Wahab, AA, El-Sayed, A. 1981. Corrosion, 37, 557.

[25] El-Sayed, A., Mohran, H. S., Abd El-Lateef, H.M., 2010. The inhibition effect of 2,4,6-tris (2-pyridyl)-1,3,5-triazine on corrosion of tin, indium and tin-indium alloys in hydrochloric acid solution, $\square$ Corros. Sci., 52, 1976-1984.

[26] Staicopolus, N., 1963. J. Electrochem. Soc. 110,1121-1124.

[27] Crolet, J, Thevenot, N., Nesic, S., 1998. Corrosion, 54, 194-203.

[28] Ogundele, G, I,, White, W.E., 1986. Corrosion, 42, (2) 71.

[29] Rosen, M.J., Surfactants and Interfacial Phenomena, John Wiley and Sons Inc., New York, 1978.

[30] Al-Sabagh, A,M., Abd-El-Bary, H,M., El-Ghazawy, R.A., Mishrif, M.R., Hussein, B.M., 2011. Surface active and thermodynamic properties of some surfactants derived from locally linear and heavy alkyl benzene in relation to corrosion inhibition efficiency, Materials and Corrosion 62, 11.

[31] Migahed, M.A., Mohamed, H.M., Al-Sabagh, A.M., 2003. Mater. Chem. Phys. 80, 169. 


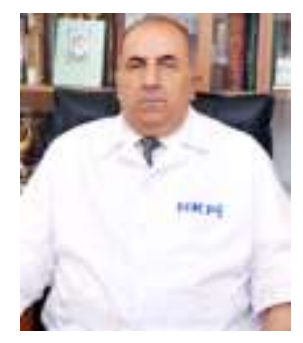

Prof. Dr. Vagif Maharram Abbasov Doctor of chemical sciences (DSC), Azerbaijan National Academy of Sciences, Institute of Petrochemical Processes, Director of Institute of Petrochemical Processes. He is a Member of the Editorial Board of "Processes of Petrochemistry and oil refining journal" (Chief Secretary). He is a Member of the American Chemical Society. He is an author on 250 papers in international journals and more than 35 books. V. M. Abbasov has carried out the thorough researches in the field of synthesis of antistatic additives to hydrocarbon liquids including to jet fuels. He for the first time proposed the possibility for producing the displaced complexes of nitroalkanes and organic acids with the transition metals, developed on their basis the high efficient and polyfunctional antistatic additive. This additive was tested and commercialized in perm plant of aircraft engines. V. M. Abbasov with coworkers has created in 1997 the polyfunctional waxy deposit corrosion inhibitor "Parkorin-1", the commercial tests have been carried out in the Azerbaijan oil fields, jointly exploited by Turkish- Azerbaijan and by TSNIIKP (Moscow city) has been recommended for application.

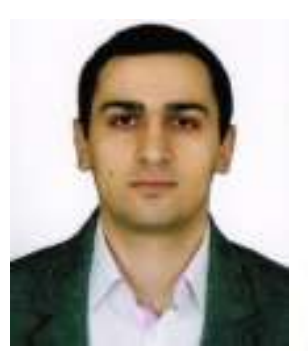

Dr. I. T. Ismayilov' Post-Doctoral Associate, Moscow State University, Doctor of chemical sciences- Azerbaijan National Academy of Sciences, Institute of Petrochemical Processes. He is an author on 50 papers in international journals. I. T. Ismayilov has carried out the thorough and extensive researches in the field of creation of the corrosion inhibitors and obtained the following important results: on the basis of carbamide and amines there has beer created a new method for synthesis of phosphate complexes and organized on their basis the production and application of polyfunctional corrosion inhibitors.

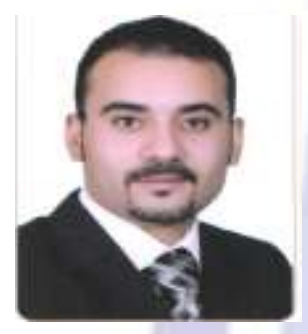

Dr. Hany M. Abd El-Lateef was born in Sohag, Egypt, in 1982. He received the master degree in physical chemistry from the University of Sohag, Sohag, Egypt, in 2009, since that has worked in different projects in the filed of corrosion science. In 2010, he joined the department of chemical resistance of materials and corrosion protection, institute of petrochemical processes, Azerbaijan National Academy of Sciences, as a PhD student. He is one of the Editorial board of Chemistry Journal. He is an author on 30 papers in international journals and two books. Hany is one of NACE membership.

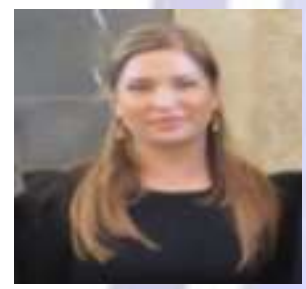

Dr. S. A. Mamedxanov, Doctor of chemical sciences, Azerbaijan State Oil Academy. She is an author on 50 papers in international journals. She obtained degree in Master of Science in Petrochemistry from Azerbaijan State Oil Academy. She received his first degree in applied chemistry from Azerbaijan State Oil Academy. Her research is focused on the Synthesis of various surfactants, compounds soluble in oils and fuels, and their investigation as corrosion inhibitors, additives to fuels, oils, polymeric stabilizers, development of theoretical bases for selecting corrosion inhibitors and additives.

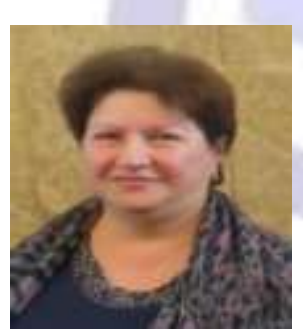

Prof. Dr. Leylufer Imran Aliyeva Doctor of Technical Sciences, Azerbaijan National Academy of Sciences, Institute of Petrochemical Processes, Head of department. She is a Member of the Editorial Board of "Processes of Petrochemistry and oil refining journal". She is an author on 180 papers in international journals and more than 18 books. Her work focused on the synthesis of nitroalkanes metallocomplexes, high-molecular amines and creation of polyfunctional antistatic additives, corrosion inhibitors, inhibitor-bactericides and study of their action mechanism. She has created the high efficient polyfunctional sulfurated hydrogen corrosion inhibitors based on a-olifins with working capacity in the media with $\mathrm{H}_{2} \mathrm{~S}, \mathrm{CO}_{2}$ content more than $25 \%$ vol.

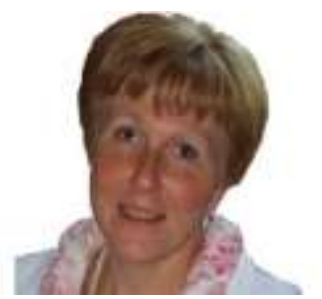

\section{Efremenko Elena Nikolaevna}

Ph.D., D.Sc., Professor, Head of the Laboratory of Ecobiocatalysis

Moscow State University. Shee is an author on 100 papers in international journals. 